\title{
Purification and assay of secretory lithostathine in human pancreatic juice by fast protein liquid chromatography
}

\author{
A Mariani, G Mezzi, A Malesci
}

\begin{abstract}
Impaired secretion of lithostathine, a pancreatic glycoprotein capable of inhibiting the growth of $\mathrm{CaCO} 3$ crystals, has been reported in chronic calcifying pancreatitis. Controversial results were obtained, however, using immunoassays with different antibodies. The aim of this study was to purify and to measure juice lithostathine by a non-immunological method. Fast protein liquid chromatography (FPLC) on a cation exchange column eluted by a sodium chloride gradient, was used. The conditions appropriate to separate secretory (S) from hydrolysed $(\mathbf{H})$ isoforms of immunopurified lithostathine were also used for juice analysis. Pancreatic juice was collected by endoscopic cannulation of the major pancreatic duct, after secretin stimulation, from eight patients with chronic pancreatitis (CP) and from eight controls. In all samples, S-isoforms of lithostathine (ranging from 16 to $19 \mathrm{Mr}$ at SDS-PAGE) were the only constituent of two of the 15 peaks in which FPLC resolved the pancreatic proteins. The nature of these two peaks was confirmed by their coelution with immunopurified S-lithostathine and by immunoblot analysis with polyclonal anti-lithostathine antibodies. The ratio between the area of S-lithostathine peaks and the total area of proteic eluates, was always lower in CP patients $(5.3 \mu \mathrm{g} / \mathrm{mg}$ of protein, median value; $0 \cdot 2-15 \cdot 4$, range) than in controls $(35 \cdot 2 \mu \mathrm{g} / \mathrm{mg} ; 16 \cdot 6-55 \cdot 9)$. It is concluded that lithostathine can be purified and measured in pancreatic juice by FPLC. Our results with a nonimmunological assay confirm a reduced secretion of lithostathine in patients with CP.

(Gut 1995; 36: 622-629)
\end{abstract}

San Paolo Institute for Biomedical Sciences and Postgraduate School of

Gastroenterology, University of Milan, Italy

A Marian

G Mezzi

A Malesci

Correspondence to:

Dr A Malesci, Postgraduate School of Gastroenterology, Via Pace 9, 20122, Milan,

Accepted for publication 15 July 1994
Keywords: lithostathine, pancreatitis, fast protein liquid chromatography.

Lithostathine, a pancreatic secretory protein originally purified from pancreatic stones, ${ }^{1}$ has been recently shown to inhibit nucleation and crystal growth of calcium carbonate. ${ }^{2}$ Thus, lithostathine is currently postulated to prevent calcic lithogenesis in the normally supersaturated pancreatic juice. At least four isoforms of lithostathine (lithostathine secretory S2-5), corresponding to various degrees of glycosylation of the same polypeptide backbone, are secreted by the pancreas. ${ }^{34}$ Mild trypsinisation of the native protein produces a cleavage of the polypeptide in position $11-12,{ }^{5}$ thus originating two fragments (lithostathine hydrolysed forms): the $N$-terminal hydrophilic undecapeptide (lithostathine H1), which bears the carbohydrate moiety and retains the inhibitory properties on the crystal growth, and a biologically inactive ${ }^{2}$ and poorly soluble ${ }^{6} 7$ sequence of 133 aminoacids (lithostathine $\mathrm{H} 2$ ).

The occurrence of an impaired secretion of lithostathine in patients with calcifying chronic pancreatitis (CP) is controversial. Decreased concentrations of lithostathine in the pancreatic juice and of lithostathine-mRNA in the pancreas of CP patients were first reported. ${ }^{89}$ Subsequent studies with immunoassay, however, failed to confirm a difference in juice concentrations between patients and controls. ${ }^{1011}$ A different specificity of the antibodies for the various lithostathine-isoforms is thought to account for these conflicting results. ${ }^{12} 13$

The primary aim of this investigation was to develop a fast protein liquid chromatography (FPLC) technique capable of purifying and measuring secretory lithostathine in human pure pancreatic juice by a non-immunological method. The comparison of juice concentrations of lithostathine in patients with CP and in controls was also planned.

\section{Methods}

IMMUNOPURIFIED LITHOSTATHINE

Pure lithostathine was a gift from Dr J P Bernard from the U-315 INSERM laboratory of Marseille, where the protein had been purified from pooled pancreatic juices by an affinity column bearing an anti-lithostathine polyclonal antibody, as previously described. ${ }^{3}$ The purity and the concentration of the peptide preparation were tested by aminoacid analysis on a Beckman System 6300 analyser (Beckman Instruments, San Ramon, CA).

Three samples of immunopurified lithostathine, differently treated after immunopurification, were tested by FPLC. The first sample had been collected in a mixture of protease inhibitors (diisopropylfluorophosphate $1 \mathrm{mM}$, 3-phenylpropionate $2 \mathrm{mM}$, benzoylarginine $0.5 \mathrm{mM}$, benzamidine $5 \mathrm{mM}$ ), and then freeze dried and stored at $-20^{\circ} \mathrm{C}$. A second sample had been similarly collected but stored as a solution, which had been thawed several times before FPLC analysis. A third sample had been collected and stored in the absence of protease inhibitors. 
PANCREATIC JUICE COLLECTION

Pure pancreatic juice was collected by selective endoscopic cannulation of the major pancreatic duct, in the three minutes after the intravenous injection of $1 \mathrm{U} / \mathrm{kg}$ of secretin (Sekretolin Diagnosticum, Hoechst, Mannheim). At time of endoscopy, patients were treated with intravenous injection of diazepam $(10 \mathrm{mg})$ and hyoscine butylbromure $(40 \mathrm{mg})$. No visual evidence of bile contamination was present in the pancreatic juice. The injection of contrast medium into the pancreatic duct for diagnostic purposes always followed the juice collection.

Juice samples were collected in iced tubes containing diisopropyl-fluorophosphate at a final concentration of $1 \mathrm{mM}$. Each sample was then centrifuged at $750 \mathrm{~g}$ at $4^{\circ} \mathrm{C}$ for three minutes; supernatants were aliquoted and their total protein content was measured. ${ }^{14}$ Before storage at $-80^{\circ} \mathrm{C}$, an aliquot of each juice sample was tested for chymotryptic activity (titrimetric method; $N$-alpha-p-tosyl-1-arginine methyl ester, Sigma, USA, as a substrate). Only samples totally devoid of chymotryptic activity were stored for the purposes of this study. The absence of chymotryptic activity in the juice samples was again tested before FPLC.

\section{FPLC METHOD}

A FPLC system made by an injector (Waters WISP 710B, standard loop $200 \mu \mathrm{l}$ ), two pumps (Waters Model 510), a LC-Spectrophotometer 481 (Lambda Max), a fraction collector (LKB, Redirac 1000), a gradient controller and chromatogram analyser (NEC APC IV; Baseline 810 Chromatography Workstation), was used.

The following experimental conditions were found appropriate to separate $\mathrm{S}$ from $\mathrm{H}$ isoforms of immunopurified lithostathine and then adopted for fractionation of juice samples. Thirty $\mu \mathrm{g}$ of immunopurified lithostathine or $200 \mu l$ of pure pancreatic juice diluted in equal amounts of buffer (sodium acetate $50 \mathrm{mM}, \mathrm{pH} 5 \cdot 0$ ) were applied to a Mono-S HR 5/5 cation exchange column (Pharmacia, LKB, Uppsala, Sweden). The column was eluted by a two step $\mathrm{NaCl}$ gradient (from 0.1 to $0.2 \mathrm{M}$ in 30 minutes and then to $1.0 \mathrm{M}$ in the following 30 minutes, this molarity being maintained up to 70 minutes). The flow rate was $1.0 \mathrm{ml} / \mathrm{min}$. Each run took 80 minutes (including a 10 minute wash out).

The FPLC eluate was monitored by the spectrophotometer set at $280 \mathrm{~nm}$ for protein detection. The integrated area of each proteic peak on the ultraviolet chromatogram was calculated by computer assistance (volt/s). The eluates corresponding to definite peaks were collected in single iced tubes to which diisopropyl-fluorophosphate was added up to a final concentration of $1 \mathrm{mM}$. Fractions were then concentrated and desalted by filtration (Ultrafree PB-10 Kd filters, Millipore, Bedford, USA).
CHARACTERISATION OF FPLC PROTEIC

FRACTIONS

Aliquots of each desalted and concentrated fraction were reduced by B-mercaptoetanol, denatured by sodium dodecyl-sulphate (SDS), and stored at $-80^{\circ} \mathrm{C}$ until tested by polyacrylamide gel (PAGE) and western blot electrophoresis. The SDS-PAGE and the electrophoretic run preliminary to the western blot were performed at the same time in two different slabs of the same cell (Protean II BioRad, Richmond, USA). PAGE was carried out in $15 \%$ acrylamide gels according to Laemmli. ${ }^{15}$ Electrophoretic bands were stained with Coomassie blue R-250. The molecular weight of each proteic band, as determined by commercial standards (Pharmacia, Uppsala, Sweden), was used to identify pancreatic proteins according to Schelle et al. ${ }^{16}$

The western blot was performed by transferring proteins from SDS-PAGE to nitrocellulose sheets according to Burnette. ${ }^{17}$ The transferred proteins were first incubated with rabbit anti-lithostathine antibody (kindly provided by Dr J P Bernard, Marseille), diluted 1 to 400 , and then treated with a peroxydase labelled antirabbit Fab preparation (Nordic). The peroxydase activity was shown by hydrogen peroxide in the presence of diaminobenzidine.

Aliquots of each juice fraction were also tested for enzymatic activity of amylase (colorimetric test, Boehringer, Mannheim), lipase (titrimetric method; triolein/tauroglycocolate, as a substate), chymotrypsin (titrimetric method; see above), and for immunoreactivity of trypsinogen (RIA, Sorin-Biomedica, Saluggia, Italy) and of elastase I (RIA, Abbott, Rome, Italy).

\section{ASSAY OF LITHOSTATHINE IN PANCREATIC}

JUICE

The reproducibility of the FPLC chromatograms (overall area of eluted peaks and relative areas of each peak) was first assessed by running six times the same sample of pancreatic juice. The ratio between the area of the peaks coeluting with the $S$ isoforms of immunopurified lithostathine and the overall area of proteic eluates at FPLC was then determined for each sample.

A reference curve plotting the cumulative area of the $S$ lithostathine peaks versus known amounts of immunopurified protein (from $50 \mathrm{pg}$ to $50 \mu \mathrm{g}$ ) applied to the column, was also constructed. The recovery of lithostathine in the juice assay was tested by adding various amounts of immunopurified $S$ lithostathine $(12 \cdot 5,25$, and $50 \mu \mathrm{g})$ to a sample of pancreatic juice.

Absolute concentrations of juice $S$ lithostathine were calculated by multiplying the $S$ lithostathine/total protein ratio for the total protein content of the juice sample or by reference to the standard curve.

PATIENTS

Pure pancreatic juice was collected from 46 


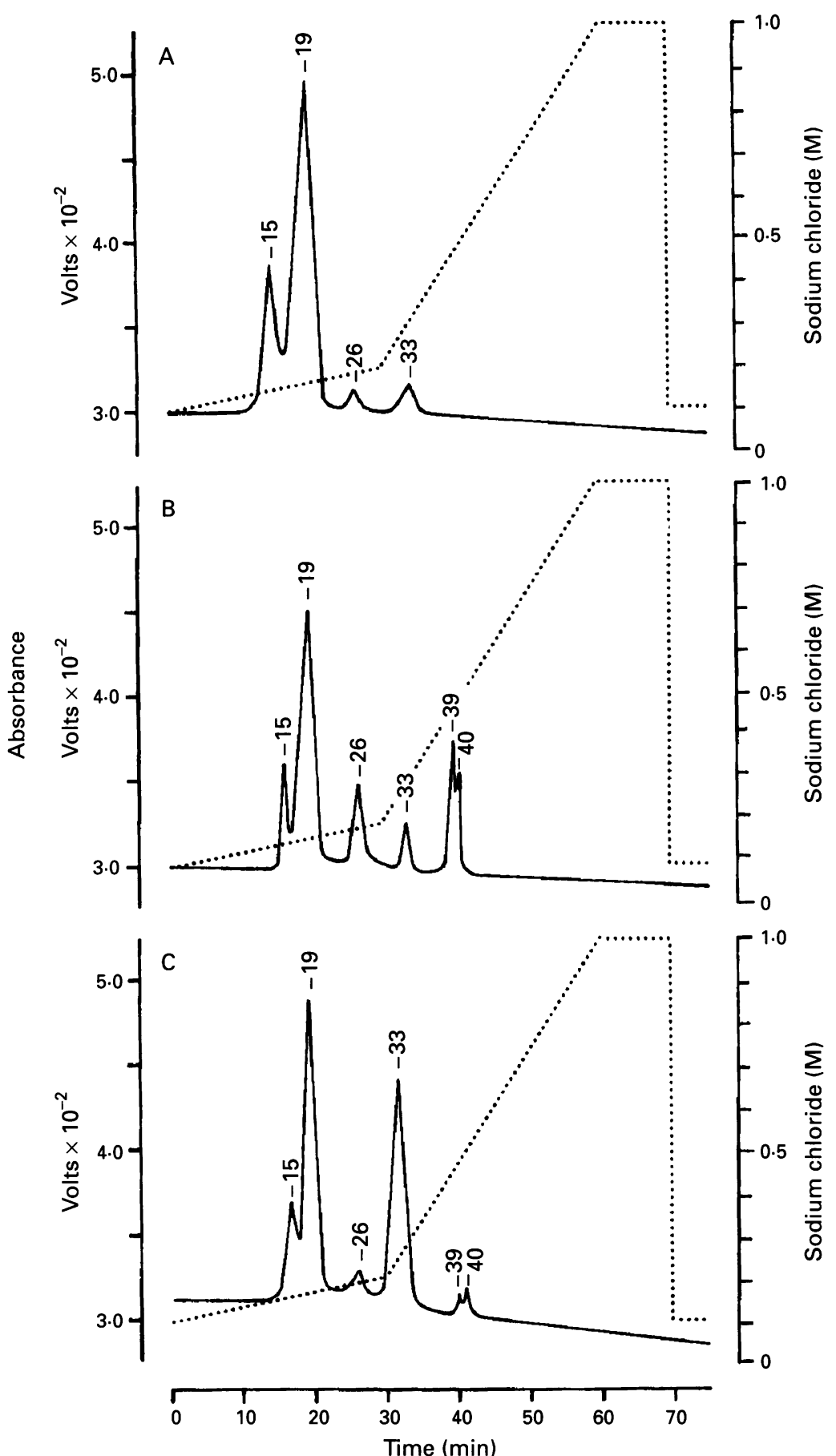

Figure 1: FPLC chromatograms of three samples of immunopurified lithostathine. (A) Sample preserved with protease inhibitors and stored at $-20^{\circ} \mathrm{C}$ as a lyophilised powder. (B) Sample preserved with protease inhibitors but stored as a repeatedly thawed solution. (C) Sample not preserved with protease inhibitors. The elution time (min) is shown on the top of each peak. The dotted line denotes the two step gradient of sodium chloride.

patients in whom a diagnostic endoscopic retrograde cholangiopancreatography (ERCP) had been requested. Juice devoid of any tryptic activity, however, was obtained only in 16 patients whose final diagnosis was CP in eight cases, acute recurrent pancreatitis in two, biliary lithiasis in two, chronic alcoholism without signs of pancreatitis in two, and irritable bowel syndrome in two cases. All patients gave their informed and written consent for the investigation.

In all cases the diagnosis of calcifying $\mathrm{CP}$ was based on clinical presentation and on typical abnormalities at ERCP. ${ }^{18} 19$ All CP patients were men (mean age 45 years, range
22-62). The aetiology of CP was alcoholic in five patients (ethanol intake $>80 \mathrm{~g} /$ day) and idiopathic in three. In one patient with idiopathic CP associated to pancreas divisum, ERCP excluded obstructive pancreatitis. Radio-opaque calcifications of the pancreas were reported only in four patients (three alcoholic and one idiopathic). Two patients had steatorrhoea and two had pancreatic diabetes.

The mean age of controls (seven men and one woman) was 47 years (range 37-55). The diagnosis of acute recurrent pancreatitis was based on the recurrence of abdominal pain with increased plasma pancreatic enzymes and with ultrasonographic evidence of pancreatic oedema and of biliary stones or sludge. The two patients with biliary stones had no evidence or history of pancreatic disease. the two alcoholic patients had no episode of abdominal pain in their medical history, a normal ERCP, and no pancreatic calcification. The diagnosis of irritable bowel syndrome was made after a thorough negative investigation for recurrent abdominal pain.

\section{STATISTICAL ANALYSIS}

The coefficient of variation (SD/mean $\times 100$ ) of the total area of intravenous peaks and of the relative areas of each peak at six FPLC runs of the same juice sample, was determined.

The Pearson correlation coefficient between the amount of juice protein injected into the FPLC column and the overall area of intravenous peaks was also calculated.

Simple regression analysis was applied to the reference curve plotting the area of $S$ lithostathine peaks at FPLC versus known amounts of applied standard.

The values of the relative areas of FPLC peaks as well as the absolute juice concentrations of $S$ lithostathine in the two subgroups of patients (CP and controls) were compared by non-parametric statistical analysis (MannWhitney test).

\section{Results}

FPLC OF IMMUNOPURIFIED LITHOSTATHINE

Figure 1 shows the chromatograms of three differently treated samples of purified lithostathine. The immunopurificate that had been collected with protease inhibitors and then stored at $-20^{\circ} \mathrm{C}$ as a lyophilised powder, resolved in two peaks eluting at 15 and $19 \mathrm{~min}$ utes and accounting for $95 \%$ of the applied protein $(22 \%$ and $73 \%$, respectively). Only trace amounts of protein were eluted at 26 and 33 minutes (Fig 1A). A lower recovery of the protein in the two major peaks $(83 \%)$ and the presence of additional definite peaks eluting at 26 minutes $(7 \%), 33$ minutes $(4 \%)$, and $39-40$ minutes $(6 \%)$, characterised the chromatogram of a sample of immunopurified lithostathine stored as a repeatedly thawed solution (Fig 1B). A similar multipeak FPLC pattern was found when the immunopurification of lithostathine had been performed in the 


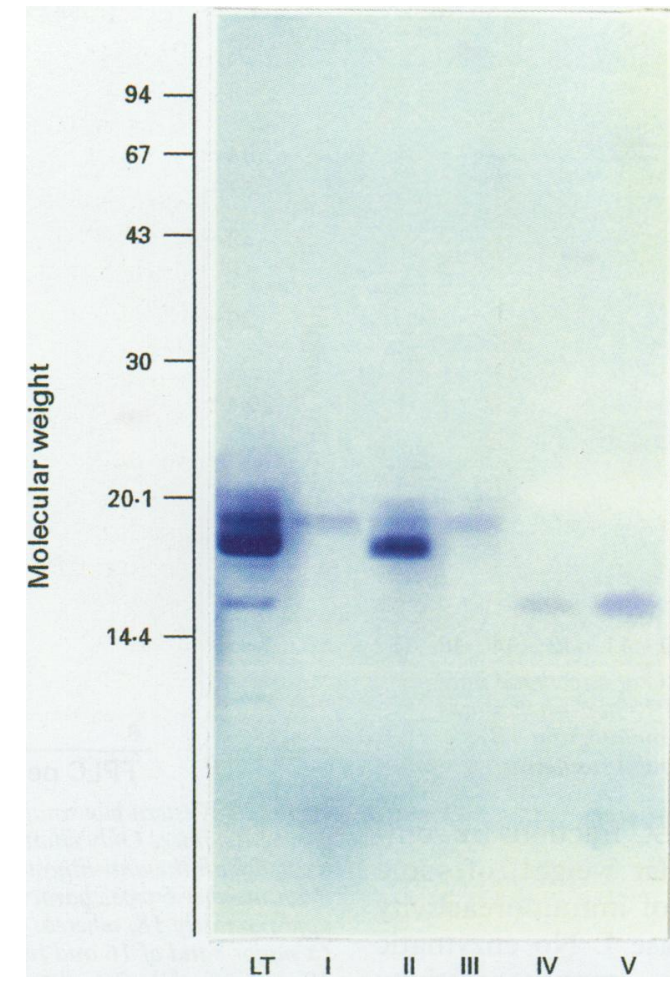

Figure 2: SDS-PAGE characterisation of FPLC fractions from immunopurified lithostathine. The pattern of the eluates from a repeatedly thawed sample, in which all peaks were adequately represented (see chromatogram of Fig 1B), is shown. The reference molecular weights were obtained by electrophoresis of standard proteins. $L T=$ non-fractionated sample. I to V, FPLC fractions eluting at 15 (I), 19 (II), 26 (III), 33 (IV), and 39-40 (V) minutes.

absence of protease inhibitors: $7 \%$ of the protein eluted at 15 minutes, $44 \%$ at 19 minutes, $2 \%$ at 26 minutes, $45 \%$ at 33 minutes, and $2 \%$ at 39-40 minutes (Fig 1C).

Figure 2 shows the SDS-PAGE patterns of the eluates corresponding to the various FPLC peaks of immunopurified lithostathine (chromatogram of Fig 1B). Both the 15 minute and the 26 minute peaks were characterised as a single band of about 18 molecular weight. The electrophoresis of the 19 minute fraction resolved a major band of 16 and two faint bands of 18 and 19. The 33 minute and the 40 minute peak produced only a single band of approximately 15 . All isoforms were recovered at SDS-PAGE of non-fractionated lithostathine. The western blot analysis confirmed all the electrophoretic bands to be immunoreactive toward the anti-lithostathine polyclonal antibody.

FPLC OF JUICE SAMPLES

Fifteen peaks eluting between 1 and 55 minutes, were detected by ultraviolet absorption at FPLC of each juice sample (Fig 3 shows the chromatogram from a control patient). Peaks numbers 6 and 7 were found to coelute with $S$ isoforms of immunopurified lithostathine.

The coefficient of variation of the total area of eluted peaks at six runs of the same juice sample was always lower than $5 \%$. The overall area of ultraviolet peaks correlated with the protein content of the juice sample $(r=0.99)$. The interassay variation of the relative areas of peaks numbers 6 and 7 was less than $3 \%$.

Figure 4 illustrates the SDS-PAGE pattern of the FPLC peaks eluted from a sample of pancreatic juice. The eluate of peak number 1 was characterised by multiple proteic bands, none of which were in the 15-20 region. Conversely, most of the other FPLC fractions were found to contain a single protein. Peak number 6 was characterised by a single electrophoretic spot of 18, whereas SDS-PAGE of peak number 7 resolved only a 16 band.

The Table shows the results of the

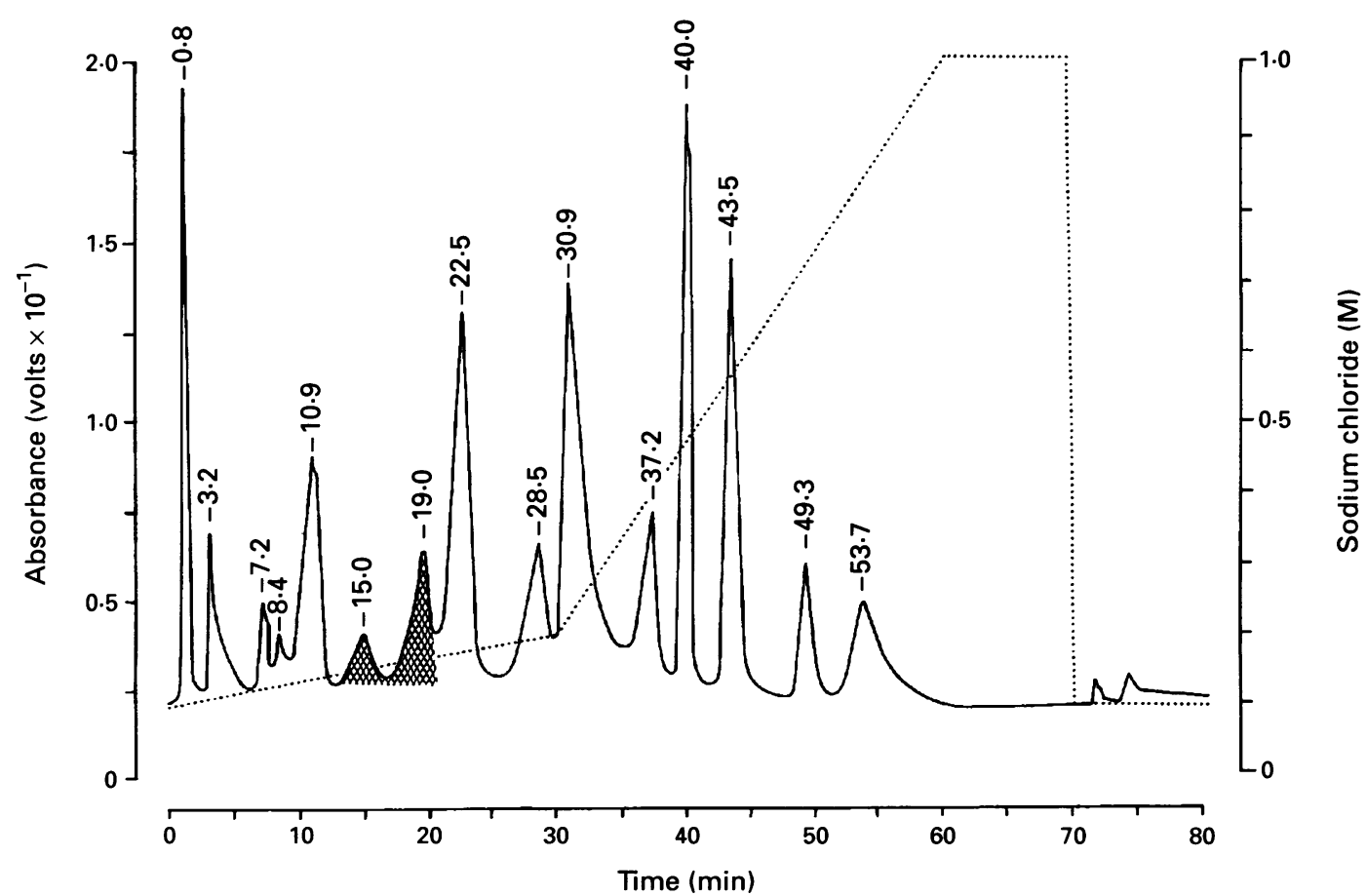

Figure 3: FPLC chromatogram of a sample of pancreatic juice from a control patient. The elution time is reported to the top of each of the 15 resolved peaks. The dashed peaks coeluted with the two major peaks of non-degradated pure lithostathine (see chromatogram in Fig 1A). The dotted line denotes the two step gradient of sodium chloride. 


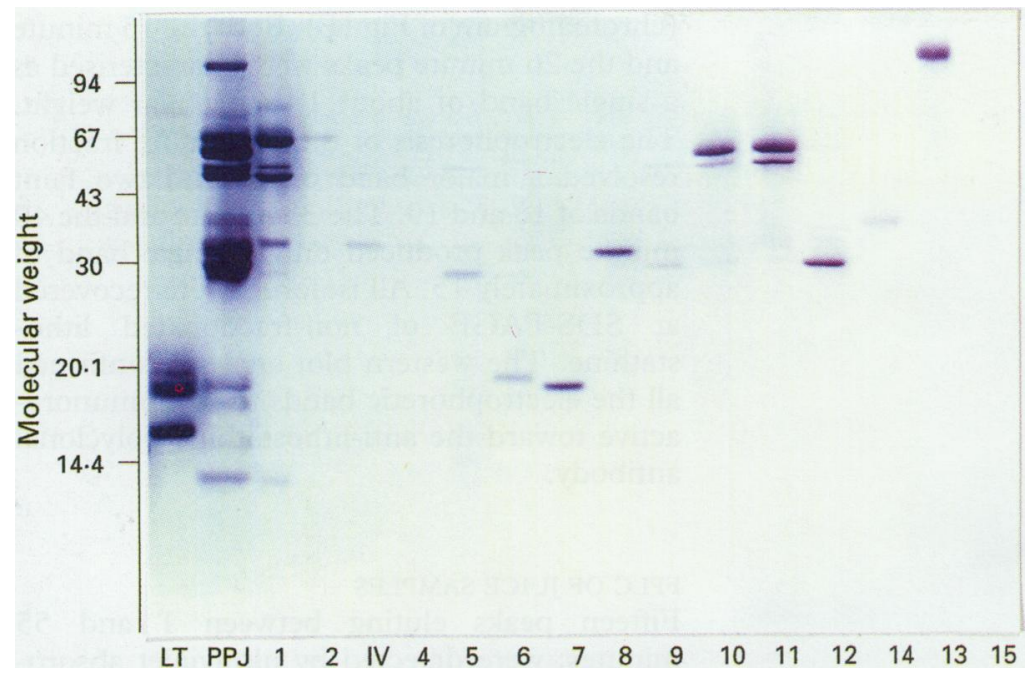

Figure 4: SDS-PAGE characterisation of peaks obtained at FPLC of pancreatic juice. Lane numbers correspond to each peak in the elution sequence. $P P F=n o n$-fractionated pancreatic juice. LT=immunopurified lithostathine (sample of chromatogram 1B). Molecular weights were obtained in comparison with molecular weight standards.

characterisation of the FPLC fractions by combined analysis of molecular weight, of some enzymatic activities, and of immunoreactivity for trypsinogen and elastase I. No enzymatic activity nor trypsinogen immunoreactivity were detected in fractions number 6 and 7 .

At immunoblot with polyclonal lithostathine antibody, only eluates from peak number 6 and 7 showed reactive bands (Fig 5). The 18 band was confirmed to be the only lithostathine isoform present in peak number 6. Conversely, three immunoreactive bands, two of which had not been visualised at SDSPAGE, were detected in the eluate of peak number 7: a major band of 16 and two less intense spots of 18 and 19 , respectively. The $S$ isoforms of lithostathine were also detectable at immunoblot of non-fractionated juices. No 15 lithostathine isoforms were detected in any FPLC fraction of pancreatic juice samples.

\section{ASSAY OF LITHOSTATHINE IN PANCREATIC}

JUICE

The application of increasing amounts of immunopurified lithostathine (only $S$ isoforms)

Characterisation of pancreatic juice FPLC peaks by combined analysis of molecular weight and of enzyme activity or immunoreactivity

\begin{tabular}{|c|c|c|c|c|}
\hline Peak & $\begin{array}{l}\text { Molecular } \\
\text { weight }\end{array}$ & $\begin{array}{l}\text { Enzymae } \\
\text { activity† }\end{array}$ & $R I A s \ddagger$ & Putative identity \\
\hline 19 & - & \multirow{7}{*}{ Amylase } & & \\
\hline 2 & 55000 & & & Amylase \\
\hline 3 & 31000 & & Elastase & Proelastase \\
\hline 4 & 31000 & & Elastase & Proelastase \\
\hline 5 & 26000 & & Trypsinogen & Trypsinogen \\
\hline 6 & 18000 & & & Lithostathine S \\
\hline 7 & 16000 & & & Lithostathine S \\
\hline 8 & 29000 & \multirow{4}{*}{$\begin{array}{l}\text { a-Chym } \\
\text { Lipase } \\
\text { Lipase }\end{array}$} & & Chymotrypsinogen \\
\hline 9 & 27000 & & Trypsinogen & Trypsinogen \\
\hline 10 & 50500 & & & Lipase \\
\hline 11 & 50500 & & & $\begin{array}{l}\text { Lipase } \\
\text { Procarboxynentidase }\end{array}$ \\
\hline 12 & 27000 & & Trypsinogen & $\begin{array}{l}\text { Trypsinogen } \\
\text { Thas }\end{array}$ \\
\hline 13 & 94000 & & & Glycoprotein 1 \\
\hline 14 & 36500 & & & Glycoprotein 2 \\
\hline 159 & & & & Unknown \\
\hline
\end{tabular}

^According to ref 16; tamylase, lipase, and activated chymotryptic activity (a-Chym) were measured; †cathodal trypsinogen and elastase immunoreactivity were assayed; $\$ \mathrm{mul}$ tiple bands (proteins not retained by the column); Ino band at staining with Coomassie blue.

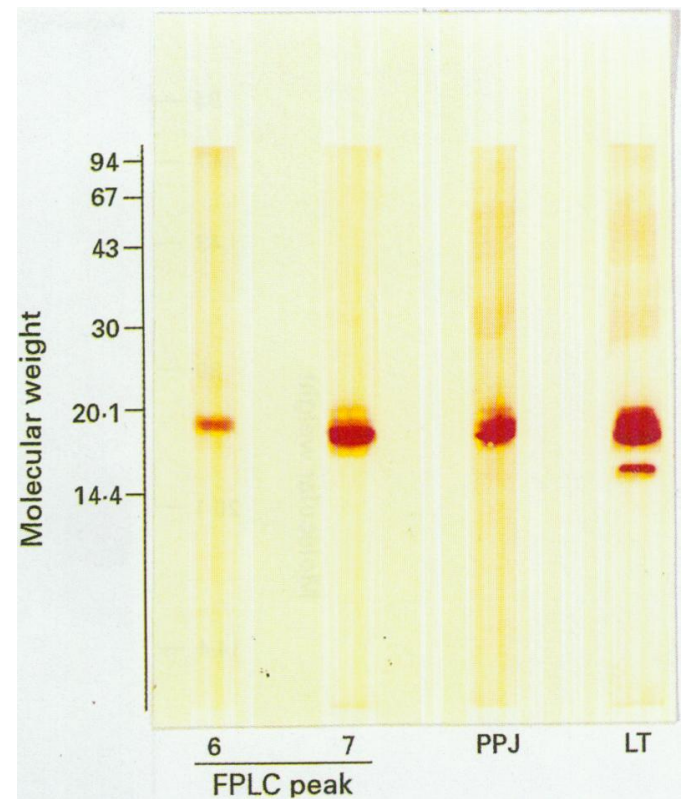

Figure 5: Western blot analysis of peaks eluted at FPLC of pancreatic juice. Only eluates from peaks numbers 6 and 7 reacted with the anti-lithostathine polyclonal antibodies. Peak number 6 was characterised by a single spot of approximately 18, whereas three immunoreactive bands (a major band of 16 and two less intense spots of 18 and 19, respectively), were detected in the eluate of peak number 7. Each of these $S$ isoforms of LT was detected at immunoblot of non-fractionated juices (PPF). Immunoblo of partially transformed pure lithostathine (LT, sample of chromatogram $1 B$ ) showed also $15 \mathrm{H}$ forms not detectable in pancreatic juice.

to the FPLC column resulted in a linear increase of the cumulative area of lithostathine peaks eluting at 15 and 19 minutes $(r=0.99)$ (Fig 6). The minimal detectable amount of lithostathine was $0 \cdot 1 \mu \mathrm{g}$. As known amounts of $S$ lithostathine were added to a sample of pancreatic juice a straight line parallel to that of the standard alone was obtained $(r=0.99)$. The recovery of the standard added to the juice ranged from $92 \%$ to $96 \%$.

The relative area of FPLC peak number 7 to the total area of proteic eluates was significantly lower $(p<0.001)$ in the juices from patients with CP $(0.24 \%$, median; $0-0.61$, range) than in those from controls $(2.35 \%$, median; $0 \cdot 65-3 \cdot 71$, range). An almost significant difference $(p=0.06)$ was found for peak number 6: $0 \cdot 20 \%(0 \cdot 01-1 \cdot 16$, range) in CP patients, versus $1.01 \%(0 \cdot 13-4.03$, range $)$ in controls. Figure 7 shows the relative concentrations of juice $S$ lithostathine $(\mu \mathrm{g} / \mathrm{mg}$ of total protein), as calculated by adding the values of the relative areas of peaks number 6 and 7. No overlap was seen between patients with $\mathrm{CP}$ and controls. Among CP patients, there was no correlation of $S$ lithostathine juice concentrations with the presence of pancreatic calcifications, with the cause of pancreatitis, and with the severity of ERCP changes. Among controls, the lowest relative concentrations of $S$ lithostathine were found in the two alcoholic patients without clinical and radiological evidence of pancreatic damage.

As the absolute juice concentrations of $S$ lithostathine $(\mu \mathrm{g} / \mathrm{ml})$ were calculated by the $S$ lithostathine/total protein ratio or by reference to the standard curve (Fig 6), a less than $10 \%$ 


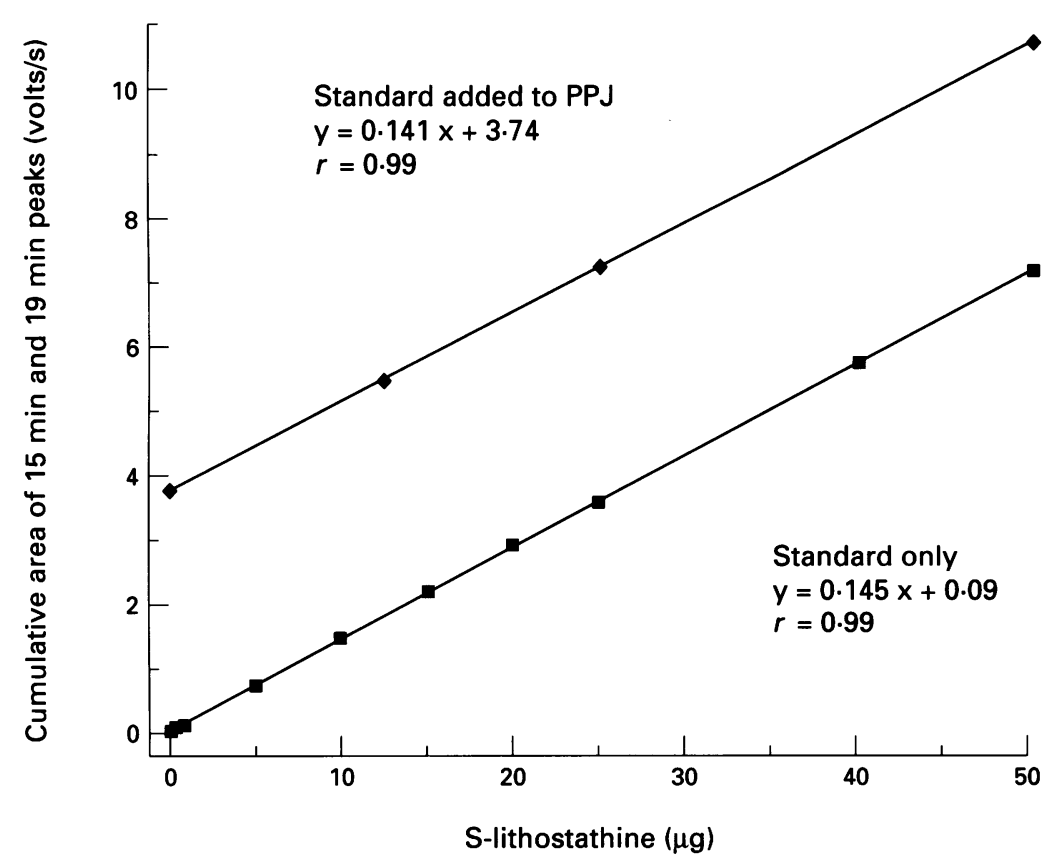

Figure 6: Reference curve of the cumulative area of FPLC peaks eluting 15 and 19 minutes after the application of known amounts of immunopurified $S$ lithostathine ( $\square)$. The minimal detectable amount was $0 \cdot 1 \mu \mathrm{g}$ of $S$ lithostathine. All experimental determinations between 1.0 and $50 \mu \mathrm{g}$ of standard fitted on the calculated regression line. As increasing amounts of standard were added to a sample of pure pancreatic juice (PPF, $\diamond)$, a nearly parallel line was obtained (recovery from 92 to 97\%).

variation in individual values was seen with the two methods. S lithostathine juice concentrations were significantly lower $(p<0.002)$ in $C P$ patients $(8 \cdot 9 \mu \mathrm{g} / \mathrm{ml}$, median; $9 \cdot 2-36 \cdot 0$, range) than in controls $(64.5 \mu \mathrm{g} / \mathrm{ml} ; 24 \cdot 9-137 \cdot 4)$. Only one of the controls (alcoholic) had an absolute juice concentration of $S$ lithostathine within the range of CP patients.

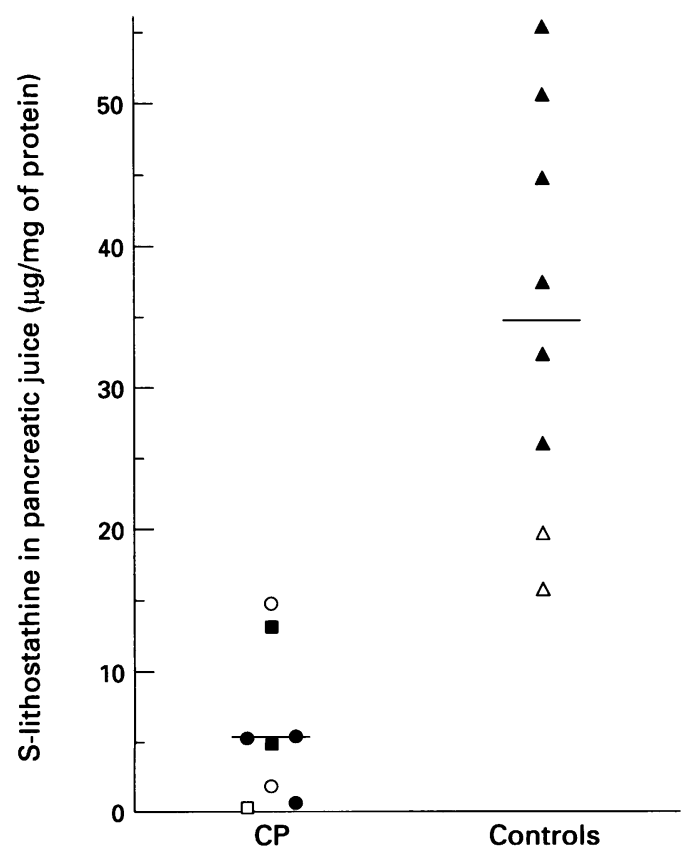

Figure 7: Relative concentration of secretory lithostathine in Figure 7: Relative concentration of secretory lithostathine (CP) and of controls. Bars show median values. In the CP column, squares show alcoholic aetiology, circles idiopathic pancreatitis, solid symbols patients with pancreatic calcifications or severe changes at ERCP, empty symbols patients with mild-moderate ductal changes. Among controls, empty triangles show alcoholic patients.
Discussion

The main aim of this study was to develop a FPLC method able to purify and quantify secretory lithostathine in human pancreatic juice. Cation exchange FPLC has been recently shown to permit a better separation of pancreatic secretory proteins ${ }^{20}$ than high performance liquid chromatography. ${ }^{21-23}$ However, none of previous chromatographic studies focused on identification and measurement of juice lithostathine.

As a first step, immunopurified lithostathine was chromatographed under different experimental conditions until an optimal resolution of secretory (18 and 16) and hydrolysed (15) isoforms was obtained and confirmed by SDSPAGE and by immunoblot. This was essential to the aim of the study because $\mathrm{S}$ and $\mathrm{H}$ isoforms have different biological and biochemical properties. If the $N$-terminal portion of the secretory forms is well established to inhibit nucleation and growth of $\mathrm{CaCO}_{3}$ crystals, ${ }^{2}$ the hydrolysed forms are actually thought to promote plugs and stone formation. ${ }^{24}$ In addition the measurement of $\mathrm{H}$ isoforms, which are polymerised and poorly soluble, ${ }^{7}$ might not be accurate even at a nonimmunological assay.

Proteases are currently assumed to play an important part in the transformation of lithostathine from $\mathrm{S}$ to $\mathrm{H}$ isoforms. A trypsin like hydrolysis of the Arg-Ile bond in position 11-12 of the native protein has been shown in vitro. ${ }^{5}$ Consistently, the FPLC analysis of purified lithostathine showed minimal amounts of $\mathrm{H}$ isoforms when the immunopurificate had been preserved with protease inhibitors and stored as a lyophilised powder, whereas a significant transformation occurred under less strict conditions of storage (Fig 1).

As the FPLC method was applied to the fractionation of pancreatic juice proteins, 15 peaks were resolved and characterised. Again, our first concern was to verify that lithostathine transformation did not occur during collection, storage, and FPLC of juice. In fact, the immunoblot revealed no 15 anti-lithostathine band in the non-fractionated juice samples, nor in their FPLC fractions (including peaks near coeluting with the $\mathrm{H}$ isoforms generated from immunopurified lithostathine). Actually, $\mathrm{H}$ isoforms, eluting at $\mathbf{4 0}$ minutes, were identified in juice samples excluded from this study because of tryptic activity (unpublished data). The post-FPLC recovery of intact proenzymes at SDS-PAGE provided additional evidence that enzymatic activation of the juice samples was adequately prevented through the entire analytical process. Another crucial point in the FPLC analysis of juice was the recovery of two definite peaks (peak numbers 6 and 7) perfectly corresponding to the peaks of secretory isoforms from immunopurified lithostathine and with identical patterns both at SDS-PAGE and at immunoblot (Figs 1 to 5).

Once the FPLC of pancreatic proteins was qualitatively satisfactory, we focused on the possibility of measuring the concentration of secretory lithostathine in pancreatic juice. In fact, the excellent reproducibility of the 
computer assisted integration of the peak areas permitted the calculation of the per cent ratio of $S$ lithostathine to total protein and then the relative concentration of juice $S$ lithostathine. The accuracy of this determination was confirmed by the finding of nearly identical results when the $S$ lithostathine concentrations were calculated by referring to a standard curve plotting the cumulative area of $S$ lithostathine peaks versus known amounts of pure standard. This, together with the very good recovery of S lithostathine standard in pancreatic juice, permitted a full validation of the assay.

Our analytical results show that $S$ isoforms of lithostathine account for no more than $5-6 \%$ of total secretory protein in subjects without pancreatic damage. In their first studies using radial immunodiffusion, De Caro and Multigner reported a higher ratio of about $15 \%{ }^{8}{ }^{25}$ Subsequently, more refined immunoassays detected relative concentrations of lithostathine in the same range of our results. ${ }^{10-12}$

Previous data from immunoassays are much more controversial about the occurrence of decreased concentrations of lithostathine in juice of patients with CP. By using polyclonal antibodies, both Multigner and ProvansalCheylan found that the amount of lithostathine, relative to total secretory protein, was decreased in CP. 812 The finding of decreased juice concentrations of encoding mRNA, ${ }^{9}$ and then the finding of a reduced synthesis of lithostathine in these patients, supported those analytical results. The same French group could not, however, confirm the difference between CP patients and controls when antilithostathine monoclonal antibodies were used for the immunoassays. ${ }^{12}$ Later, Schmiegel et al found no difference between patients and controls by using a fluorometric immunoassay with a commercial monoclonal antibody that recognises only low molecular weight hydrolised isoforms. ${ }^{11}$ To explain these discrepancies, a different affinity of monoclonal and polyclonal antibodies for the various lithostathine isoforms has been claimed. However, immunobinding studies of the single antibodies have not been made available. Therefore, the results of our non-immunological assay are particularly important as they finally confirm the association with $\mathrm{CP}$ of a decreased secretion of lithostathine and show the absence of overlapping values of juice lithostathine concentration in controls.

As to the implications of a decreased secretion of lithostathine in the pathogenesis of CP, our data do not permit final conclusions. The reduced juice concentration of the protein might play a primary part in the development of the disease or it might simply be an epiphenomenon. We did not find any correlation between the juice concentrations of lithostathine and the stage or the cause of the disease. Also Multigner et al, using an immunoassay in a larger series, found no difference in juice lithostathine between patients with alcoholic pancreatitis and those with hereditary or tropical CP, nor between patients with and those without calcifications. ${ }^{8}$
This implies that the altered expression of the lithostathine gene is an early phenomenon in the course of the disease possibly predisposing to its development. Conversely, the finding of intermediate values of relative $S$ lithostathine concentration in the pancreatic juice of alcoholic patients without pancreatitis shows that the alcohol consumption by itself can depress lithostathine secretion, regardless of the development of CP, suggesting a multifactorial pathogenesis of the disease. Alternatively, the comparatively low concentrations of lithostathine in alcoholic patients might reflect a preclinical stage of the disease.

The described non-immunological assay of secretory lithostathine, which is accurate and comparatively easy to perform, is expected to contribute to clarifying the role of this glycoprotein in the pathogenesis of CP. In particular, its application to longitudinal studies on subjects at risk of developing CP because of their drinking habits and to investigations on non-alcoholic patients with calcyfying CP is warranted. Conversely, a clinical use of the assay for diagnostic purposes seems to be greatly hampered by the tryptic activation often occurring during the endoscopic collection of pure pancreatic juice.

The technical assistance of Luisella Arborati and Nicoletta Gagliano is gratefully acknowledged

This study was partly supported by the Italian National Research Council (CNR) and by the Ministry for University, Research and Technology.

1 De Caro A, Lohse J, Sarles H. Characterization of a protein isolated from pancreatic calculi of men suffering from chronic calcifying pancreatitis. Biochem Biophys Res Commun 1979; 87: 1176-82.

2 Bernard JP, Adrich Z, Montalto G, De Caro A, De Regg $M$, Sarles $\mathrm{H}$, et al. Inhibition of nucleation and crysta growth of calcium carbonate by human lithostathine. Gastroenterology 1992; 103: 1277-84.

3 Montalto G, Bonicel J, Multigner L, Rovery M, Sarles H, De Caro A. Partial amino acid sequence of human pancreatic stone protein, a novel pancreatic secretory protein. Biochem f 1986; 238: 227-32.

4 De Caro A, Bonicel J, Rouimi P, De Caro J, Sarles H, Rovery $M$. Complete amino acid sequence of an immunoreactive form of human pancreatic stone protein a novel pancreatic secretory protein. Eur f Biochem 1986; 168: $201-7$.

5 Rouimi P, Bonicel J, Rovery M, De Caro A. Cleavage of the Arg-Ile bond in the native polypeptide chain of human .

6 De Caro A, Adrich Z, Fournet B, Capon C, Bonicel J Ce Caro J, et al. N-terminal sequence extension in the glycosylated forms of human pancreatic stone protein. The 5 oxoproline N-terminal chain is 0 glycosylated on the 5th amino acid residue. Biochim Biophys Acta 1989; 994: $281-4$.

7 Gross J, Carlson RI, Brauer AW, Margolies MN, Warshaw $\mathrm{AL}$, Wands JR. Isolation, characterization and distribution of an unusual pancreatic human secretory protein. tion of an unusual pancreatic hum

8 Multigner L, Sarles H, Lombardo D, DeCaro A. Pancreatic stone protein II. Implication in stone formation during the course of chronic calcifying pancreatitis. Gastroenterology 1985; 89: 387-91

9 Giorgi D, Bernard JP, Rouquier S, Iovana J, Sarles H, Dagorn JC. Secretory pancreatic stone protein messenger RNA. Nucleotide sequence and expression in chronic calcifying pancreatitis. $\mathcal{f}$ Clin Invest 1989; 84: 100-6.

10 Schmiegel WH, Burchert $M$, Kalthoff $H$, Thiele HG, Butzow GH, Klose G, et al. Pancreatic stone protein in

11 serum of patients with pancreatitis. Lancet 1986; ii: 686 . , Kalthoff $\mathrm{H}$, Roeder C, Butzow $\mathrm{G}$, Grimm $\mathrm{H}$, et al. Immunochemical characterization and quantitative distribution of pancreatic stone protein in sera and pancreatic secretions in pan

12 Provansal-Cheylan M, Mariani A, Bernard JP, Sarles $H$, Dupuy P. Pancreatic stone protein: quantification in pancreatic juice by enzyme-linked immunosorbent assay and comparison with other methods. Pancreas 1989; 4

13 Dagorn JC. Lithostathine. In: Go VLW, et al, eds. The 
pancreas, biology, patholobiology and disease. New York: Raven Press, 1993: 253-63.

14 Lowry OH, Rosebrough NJ, Farr AL, Randall RJ. Protein measurement with the Folin phenol reagent. $f$ Biol Chem 1951; 192: 75 .

15 Laemmli UK. Cleavage of structural proteins during the assembly of the lead of bacteriophage T4. Nature 1970; 227: $680-5$.

16 Scheele G, Bartelt D, Bieger W. Characterization of human exocrine pancreatic proteins by two-dimensional isoelectric focusing/sodium dodecyl sulphate gel electrophoresis. Gastroenterology 1981; 80: 461-73.

17 Burnette WN. 'Western blotting'. Electrophoretic transfer of proteins from sodium dodecyl sulfate polyacrylamide gels to unmodified nitrocellulose and radiolographic detection with antibody and radioiodinated protein A. Anal Biochem 1981; 112: 195.

18 Axon ATR, Classen M, Cotton PB, Cremer M, Frenny PC Lee WR. Pancreatography in chronic pancreatitis: international definitions. Gut 1984; 25: 1107-12.

19 Sarles H. Definition and classification of chronic pancreatiis. Pancreas 1991; 6: 470-4.

20 Fuchs MJ, Keim V. Separation of rat pancreatic secretory proteins by cation-exchange fast protein liquid chromatography. $\mathcal{F}$ Chromatogr 1992; 576: 287-95.

21 Goke B, Keim V, Meier T, Arnold R, Adler G. Identification of rat pancreatic secretory proteins after separation by high performance liquid chromatography. Pancreas 1988; 3: 199-206.

22 Goke B, Keim V, Dagorn JC, Arnold R, Adler G. Resolution of human exocrine pancreatic juice proteins by reversed-phase high performance liquid chromatography (HPLC). Pancreas 1990; 5: 261-6.

23 Padfield PJ, Scheele GA. The use of two-dimensional gel electrophoresis and high-performance liquid chromaelectrophoresis and high-performance liquid chromaet al, eds. The pancreas, biology, pathobiology and disease. New York: Raven Press, 1993: 265-73.

24 Mariani A, Bernard M, Provansal-Cheylan M, Nitsche S, Sarles H. Differences of pancreatic stone morphology and content in patients with pancreatic lithiasis. Dig Dis $\mathrm{SC}_{\mathrm{C}}$ 1991; 36: 1509-16.

25 De Caro A, Multigner L, Lafont H, Lombardo D, Sarles H. The molecular characteristics of a human pancreatic acidic phosphoprotein that inhibits calcium carbonate crystal growth. Biochem f 1984; 222: 669-77. 